\title{
BREMSSTRAHLUNG OF ELECTRONS AND YIELD OF NEUTRONS FROM THICK CONVERTERS, PASSING OF GAMMA-RADIATION AND NEUTRONS THROUGH BIOLOGICAL SHIELDING
}

\author{
O.S. Deiev, G.L.Bochek, V. N.Dubina, S. K. Kiprich, \\ G.P. Vasilyev, V.I. Yalovenko, V.D. Ovchinnik, M. Y. Shulika \\ National Science Center "Kharkiv Institute of Physics and Technology", 61108, Kharkiv, Ukraine
}

(Received July 18, 2018)

In GEANT4 spectral-angular distributions of the bremsstrahlung of medium-energy electrons from amorphous targets of different thickness and atomic charge were calculated. The total yield of gamma quanta in the forward hemisphere and at large scattering angles were determined depending on the converter thickness. The difference in the characteristics of gamma radiation for thin and thick targets was shown. The neutron yield is calculated due to photonuclear reactions for various converters. Numerical estimates of the radiation spectra after passing through the biological shielding for neutron and bremsstrahlung were carried out.

PACS: 07.85.Fv, 61.80. Cb

\section{INTRODUCTION}

Calculation of the spectral-angular characteristics of the electron bremsstrahlung radiation from different targets is necessary for calculating of the gamma-radiation yield at various angles, as well as obtaining radiation spectra after passing through biological shielding. The program code GEANT4, PhysListLowEnergy allows to performs such calculations with correct consideration of all physical processes for the case of an amorphous target $[1,2]$. Similarly GEANT4, PhysListQGSPBICHP makes it possible to calculate the neutron yield due to photonuclear reactions from targets of different thickness and atomic charge. In NSCKIPT was developed the method for analyzing and optimizing of the radiation facilities with linear electron accelerators [3-5]. The method allows reach the optimal location of objects for irradiation in the field of electrons and bremsstrahlung. For example, in [6] the dependence of the yield of nuclear reactions $A(\gamma, X) B$ on a bremsstrahlung beam was calculated in GEANT4. Earlier, we calculated angular and energy distributions of the bremsstrahlung yield at small angles for the electrons with energy $300 \ldots 1200 \mathrm{MeV}$ from various converters. Angular distributions of the gamma radiation yield $N_{\gamma}(\Theta)$ were obtained, the angular width $\Theta_{1 / 2}$ was determined at half-height of the distributions [7-9]. The noticeable increase of value $\Theta_{1 / 2}$ was observed with increasing thickness and charge of the target. This is caused, mainly, by the multiple electrons scattering. There is the inverse pro- portionality of $\Theta_{1 / 2} \sim 1 / E_{e}$ at the equal converter thickness. The neutrons generation by the mediumenergy electrons and the relative intensity of gamma radiation, and the neutrons yield also depends from the thickness and atomic charge of the target $(Z)$. With the electrons energy increasing the photoneutrons yield of also increases [10]. Computer codes GEANT4 and MCNPX are used both for the calculating the gamma radiation generation and neutrons yield from the converter, and also for modeling the radiation passage through matter [11-16]. The purpose of this work is: - the calculation in GEANT4 of the bremsstrahlung spectral-angular distributions of medium-energy electrons from amorphous targets of different thickness and atomic charge; - the performing numerical estimates of the total photoneutrons yield from converters of different thickness and the calculation of the angular dependence of the neutron yield; - the performing numerical estimates of the ("residual") gamma radiation and neutrons after the passage of the biological shielding separately for the neutrons and bremsstrahlung.

\section{SPECTRAL-ANGULAR CHARACTERISTICS OF THE ELECTRONS BREMSSTRAHLUNG}

The energy and angular characteristics of the gamma radiation of the electrons with different energies from various converters were calculated similarly to $[7,8,23]$. The gamma radiation was calculated in spherical geometry for different value of the polar angle $(0 \ldots \pi$ radian $)$. The axis of the electron beam

\footnotetext{
*Corresponding author E-mail address: deev@kipt.kharkov.ua
} 
corresponds to the 0 angle. The backward direction corresponds to $\pi$ radian.

Figs.1,2 shows the calculated bremsstrahlung spectra of electrons with energy of $E_{e}=10 \mathrm{MeV}$ for different ranges of the radiation angle of gamma quanta (in radians) and two values of the Ta converter thickness: $0.1 \mathrm{~mm}$ and $2.4 \mathrm{~mm}$. Also the range of the radiation angle is shown on the Figs.1,2.

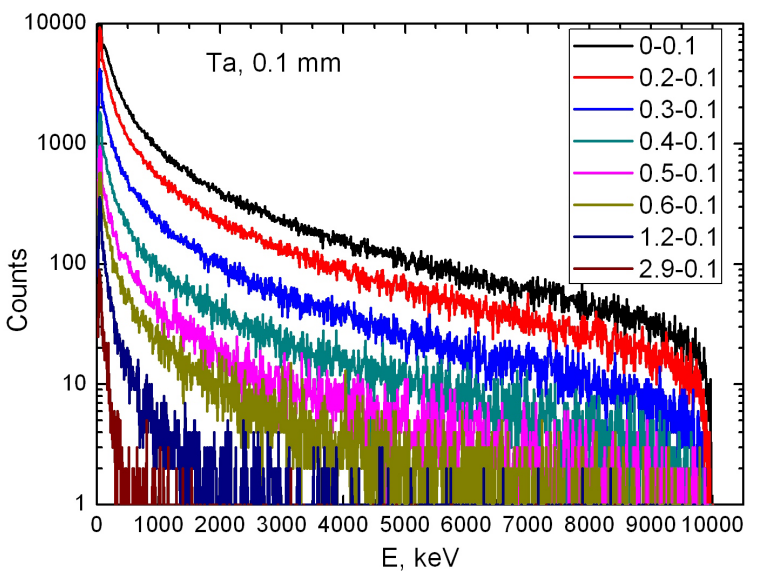

Fig.1. The calculated bremsstrahlung spectra of electrons with an energy of $E_{e}=10 \mathrm{MeV}$ for different ranges of the gamma quanta radiation angle (in radians). Ta converter thickness $0.1 \mathrm{~mm}$

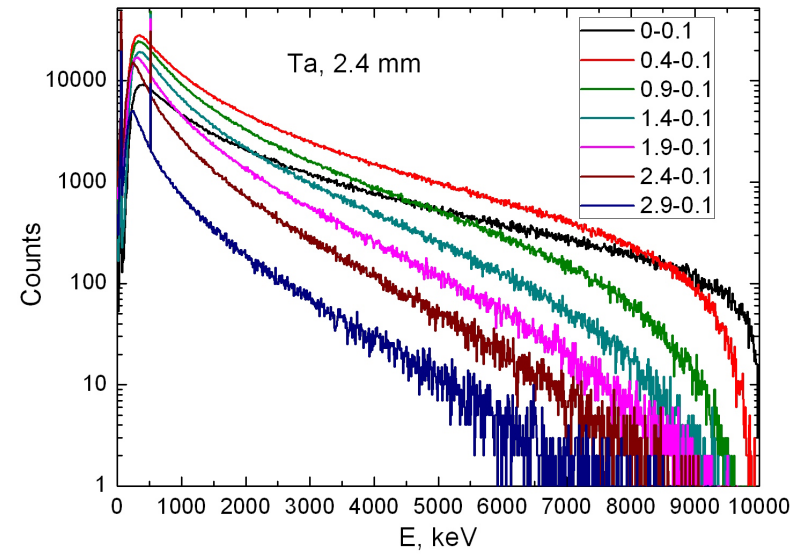

Fig.2. The calculated bremsstrahlung spectra of electrons with an energy of $E_{e}=10 \mathrm{MeV}$ for different ranges of the gamma quanta radiation angle (in radians). Ta converter thickness $2.4 \mathrm{~mm}$

As the quanta radiation angle increases, the radiation intensity substantially decreases. The number and maximum energy of the high-energy quanta in the spectrum at large angles also noticeably decreases. In addition, with the converter thickness increasing, the gamma quanta number at large angles also increases.

Fig.3 shows the ratio of the number of the bremsstrahlung gamma quanta with energy in the range $0 \ldots 1 \mathrm{MeV}$ to the total gamma quanta number as the function of the radiation angle.

At large $\left(>90^{\circ}\right)$ radiation angles, the fraction of the gamma quanta with energy in the range $0 \ldots 1 \mathrm{MeV}$ reaches 0.85 . There is a little deflection of the dependence in the region of $>90^{\circ}$ (because of the large transverse dimensions of the target). For the
Ta target with dimensions $5 \times 5 \times 0.1 \mathrm{~mm}^{3}$ and $E_{e}=10 \mathrm{MeV}$ at the radiation angle greater than $>80^{\circ}$, the fraction of gamma quanta with energy in the interval $0 \ldots 1 \mathrm{MeV}$ reaches 0.9 .

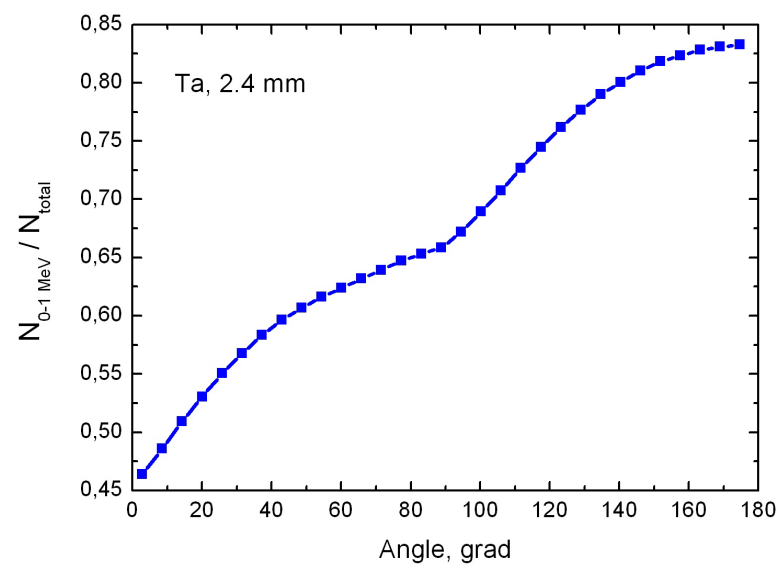

Fig.3. The ratio of the number of bremsstrahlung gamma quanta with energy in the range $0 \ldots 1 \mathrm{MeV}$ to the total gamma quanta number as the function of the radiation angle. Target $-T a$, dimension $5 \times 5 \times 2.4 \mathrm{~mm}^{3}, E_{e}=10 \mathrm{MeV}$

The gamma-ray spectra for $100 \mathrm{MeV}$ electrons were calculated and the total gamma quanta yield from various converters was determined. Fig.4 shows gamma-ray spectra for $100 \mathrm{MeV}$ electrons from the Ta target $1 \mathrm{~mm}$ and $30 \mathrm{~mm}$ thick for the radiation angle in the range $0 . .0 .1$ radian.

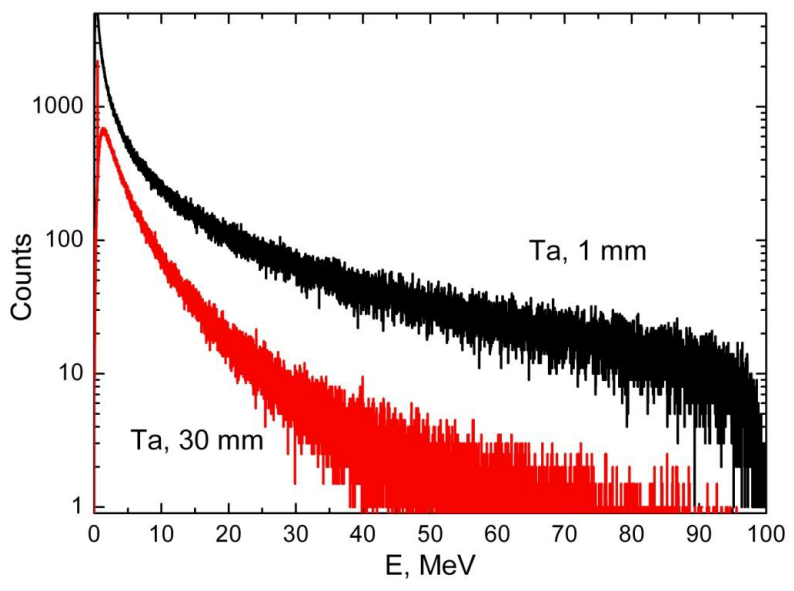

Fig.4. Bremsstrahlung spectra of the $100 \mathrm{MeV}$ electrons from the Ta target $1 \mathrm{~mm}$ and $30 \mathrm{~mm}$ thickness. The radiation angle is in the range $0 . . .0 .1$ radian

It can be seen that the gamma radiation spectra for thin and thick (several radiation lengths) converters are significantly different. With increasing target thickness, the number of high-energy quanta decreases. In the thick target high-energy quanta can produce electron-positron pairs, followed by the development of the processes of bremsstrahlung, annihilation, Compton scattering etc.

In Fig.5 shown the dependencies of the bremsstrahlung yield from the radiation angle for three gamma-ray energy intervals $0 \ldots 1,0 \ldots 10$, 
10...100 MeV. Target $T a$, thickness $1 \mathrm{~mm}, E_{e}=$ $100 \mathrm{MeV}$. It can be seen (shown by the arrow) that the number of high energy gamma quanta decreases by several orders of magnitude with increasing radiation angle. At large angles $\left(>90^{\circ}\right)$, gamma rays with low energy were mainly radiated.

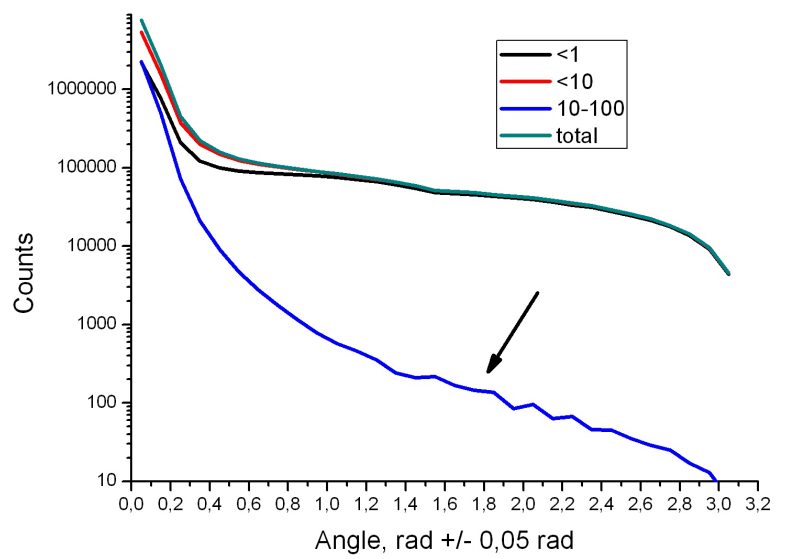

Fig.5. Dependencies of the bremsstrahlung yield from the radiation angle for three gamma-ray energy intervals $0 \ldots 1,0 \ldots 10,10 \ldots 100 \mathrm{MeV}$. Target Ta, thickness $1 \mathrm{~mm}, E_{e}=100 \mathrm{MeV}$

The total yield of the gamma quanta in the range of the radiation angle 0...0.1 radian and in the forward hemisphere $0 \ldots 1.57$ radian depending on the target thickness was calculated. In Fig.6 is shown the results of calculations for $T a, E_{e}=100 \mathrm{MeV}$. The maximum of total gamma quanta yield is somewhat different for various radiation angles: in the first case, the maximum yield was observed at the target thickness of $5 \mathrm{~mm}$, in the second case - at $10 \mathrm{~mm}$.

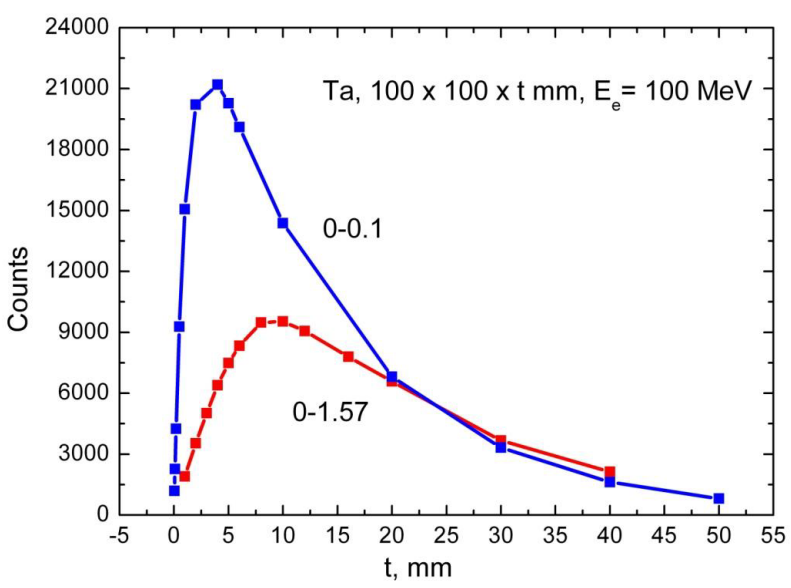

Fig.6. The total gamma quanta yield in the range of the radiation angle 0...0.1 radian and in the forward hemisphere 0...1.57 radian depending on the thickness of the Ta target, $100 \mathrm{MeV}$, different $N_{e}$

Fig.7 is shown the dependencies of the total gamma quanta yield for $\mathrm{Fe}$ and $\mathrm{C}$-converters in two ranges of the radiation radiation angle: $0 \ldots 0.1$ radian and $0 \ldots 1.57$ radian for the target $F e$ (see Fig.7,a) and $C$ (see Fig.7,b) as a function of the target thickness.

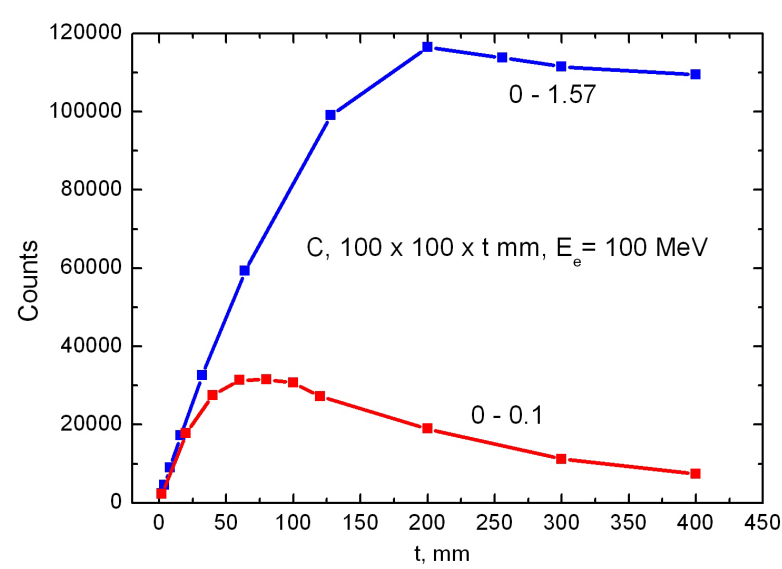

a) Fe converter

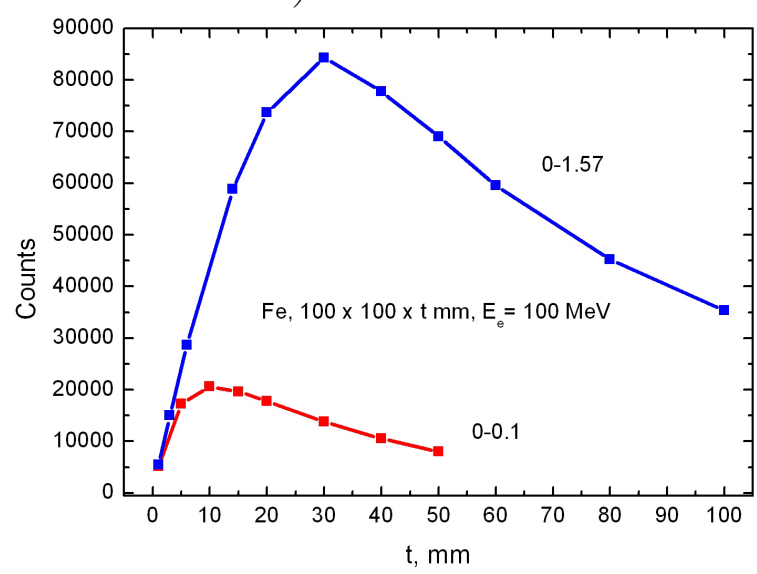

b) C converter

Fig.7. The dependencies of the total gamma quanta yield for $\mathrm{Fe}$ and $\mathrm{C}$-converters in two ranges of the radiation angle: $0 . .0 .1$ radian and $0 \ldots 1.57$ radian for the target $F e-(a)$, and for the target $C-(b)$, as the function of the target thickness, $E_{e}=100 \mathrm{MeV}$

For the $\mathrm{Fe}$ target the maximum gamma quanta yield is observed at the target thickness of $10 \mathrm{~mm}$ in the radiation angle range $0 . .0 .1$ radian and $30 \mathrm{~mm}$ in the radiation angle range $0 . .1 .57$ radian. In the radiation angle range $0 . .1 .57$ radian for target $C$, the maximum is observed at the thickness of about $\sim 200 \mathrm{~mm}$, in the radiation angle range $0 . . .0 .1$ radian, at the thickness $\sim 70 \mathrm{~mm}$.

Thus, the maximum of the total bremsstrahlung yield depends on the radiation angle and atomic target number.

The calculation of bremsstrahlung in the range of the radiation angle $45 \ldots 135^{\circ}$ (sidewards) was performed. The gamma quanta spectra from the $\mathrm{Ta}$ target of various thickness are shown in Fig.8. The transverse dimensions of the converter are fixed.It is seen from Fig. 8 that the gamma quanta spectra for the target thickness of $20 \ldots 80 \mathrm{~mm}$ practically coincide. Thus, the calculation showed that the total gamma quanta yield within the radiation angle range $45 \ldots 135^{\circ}$ (sidewards) does not decrease with increasing target thickness, but saturation occurs. 


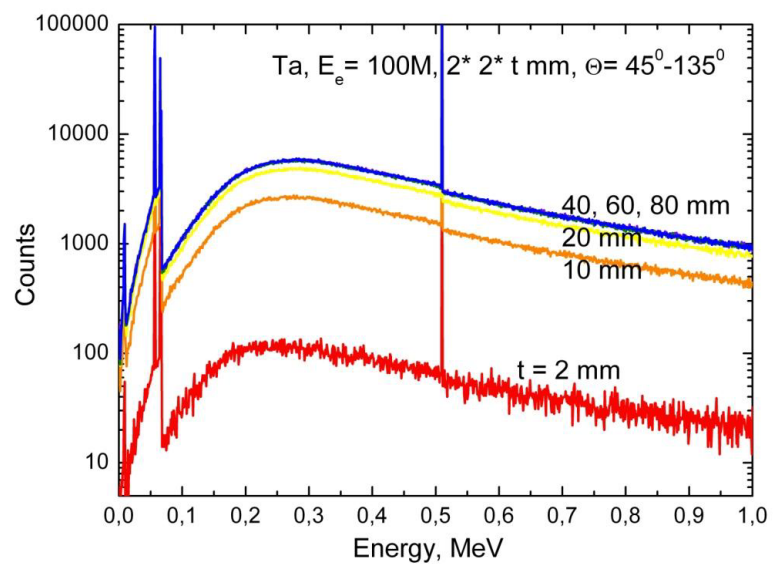

Fig.8. The bremsstrahlung spectra from the Ta target of various thickness in the range of the radiation angle $45 \ldots 135^{\circ}$ (sidewards). The transverse Ta target dimensions $2 \times 2 \mathrm{~mm}^{2}$

The gamma quanta spectra in the range of large scattering angles of $145 \ldots 180^{\circ}$ (back) from the targets of various thickness and atomic number were also calculated.

Electrons with the energy of $10,100,1000 \mathrm{MeV}$ were directed to converters from $C, S i, T a$. The form of the spectra of "backward" gamma radiation is practically the same for all values of the electron energy. In Fig.9 is shown typical gamma radiation spectra of the $100 \mathrm{MeV}$ electrons in the "backward" radiation angle. The spectra of the "scattered backward" gamma radiation (in the back hemisphere) differs for the light and heavy targets. For light converters $(C, S i)$ there are a characteristic "Compton scattering trapezoidal spectrum". The right edge of the trapezoidal spectrum in energy corresponds to the scattering of high-energy quanta $(>10 \mathrm{MeV})$ : $280.9 \mathrm{keV}$ - on an angle of $145^{\circ}$ and $255.5 \mathrm{keV}$ - on an angle of $180^{\circ}$. In the spectrum also the gamma quanta with energies higher than the Compton scattering energy and the $511 \mathrm{keV}$ line are observed. This is due to backward bremsstrahlung and annihilation of positrons.

In order to better understand the mechanism of formation of the radiation spectra of electrons in the scattering angle range of $145 \ldots 180^{\circ}$ (back), additional calculations were performed under the following conditions: 1 - all the physical processes are included, 2 -= processes are turned off: Compton and Rayleigh scattering, photoelectric effect, 3 - the difference of spectra 1 and 2 is calculated. Some results are presented in Fig.10.

Thus, the characteristic "Compton scattering trapezoidal spectrum" is better manifested on thick converters from light elements and practically stop being visible for heavy elements, where bremsstrahlung dominates at large angles. The results agree well with the data of $[7,14]$.
The backscattered radiation spectrum can be divided on four regions: the region of CXR, Compton scattering, the positron annihilation region, and the secondary bremsstrahlung region.

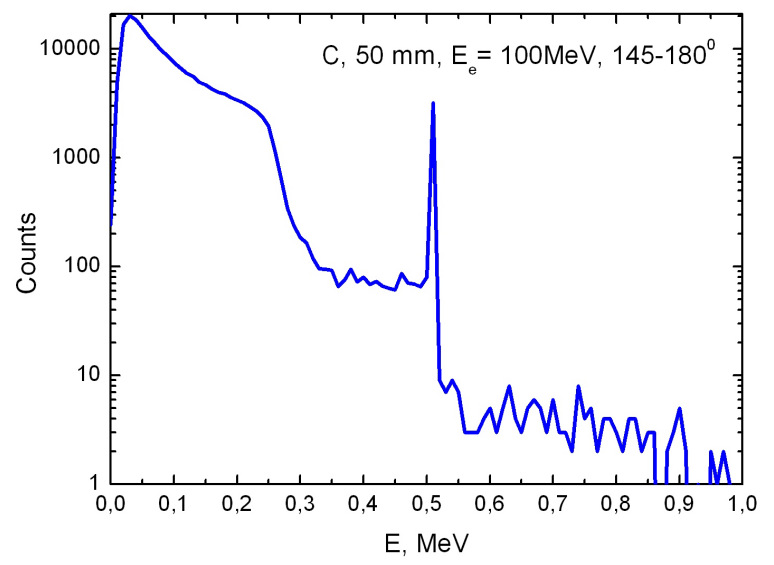

a) C target, thickness $50 \mathrm{~mm}$

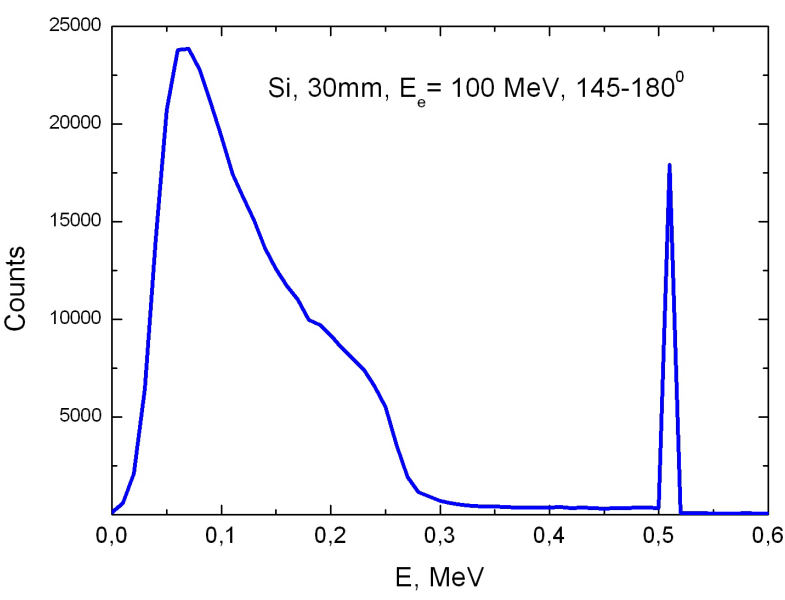

b) Si target, thickness $30 \mathrm{~mm}$

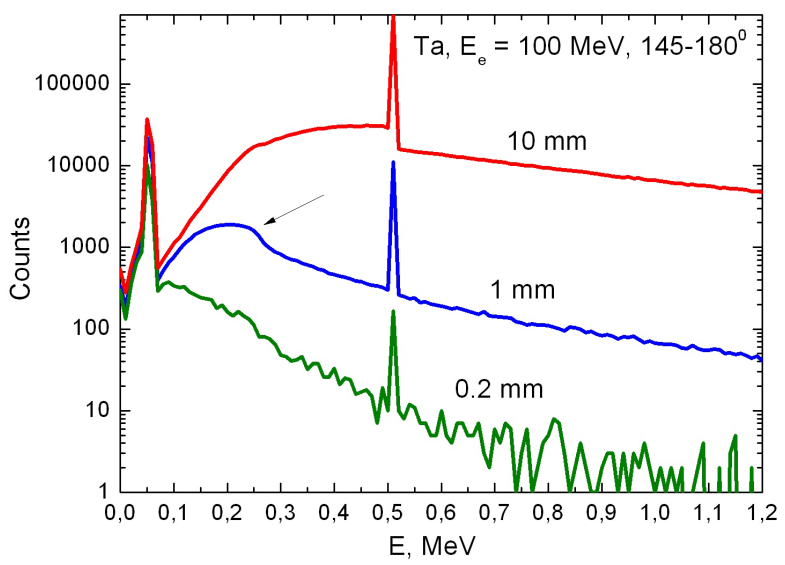

c) Ta target, thickness $0.2,1,10 \mathrm{~mm}$

Fig.9. Calculated gamma-radiation spectra of the $100 \mathrm{MeV}$ electrons in the radiation angle range of $145 \ldots 180^{\circ}$ for $C, S i$, Ta converters 


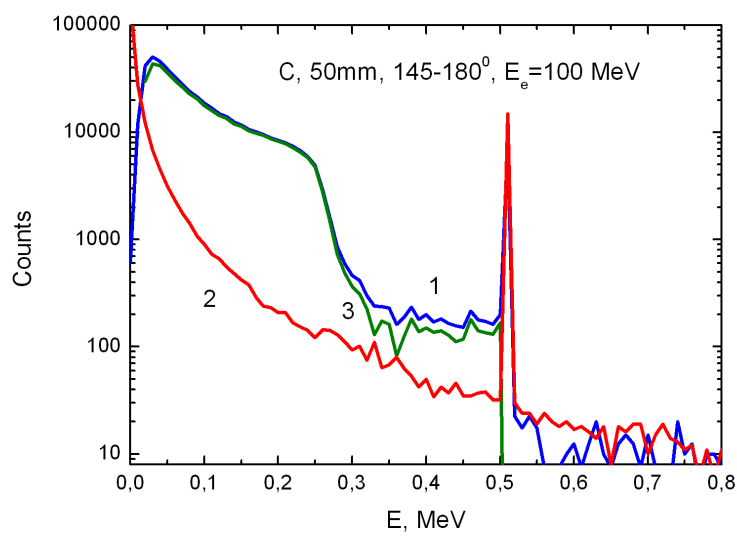

a) C target, thickness $50 \mathrm{~mm}$

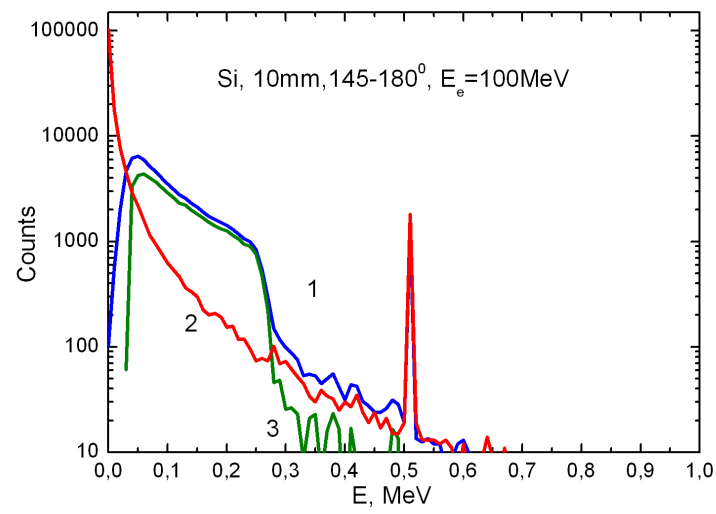

b) Si target, thickness $10 \mathrm{~mm}$

Fig.10. Radiation spectra of the $100 \mathrm{MeV}$ electrons in the scattering angle range $145 \ldots 180^{\circ}$ (back) for $C, S i$ converter: 1 - all the physical processes are included, 2 - processes are turned off: Compton and Rayleigh scattering, photoelectric effect, 3 - the difference of spectra 1 and 2

\section{CALCULATION OF NEUTRONS YIELD FROM TARGETS OF DIFFERENT THICKNESS}

In the code GEANT4, PhysListQGSPBICHP, the neutron yield due to photonuclear reactions was calculated for targets of different thickness and atomic charge. Verification of the results was performed by comparison with experiment and calculations in $M C N P X$. The calculated total neutrons yield in $4 \pi$ from the thick lead target under the action of high-energy electrons is shown in Fig.11. The results of the calculations are in good agreement with the results of the experiment [10]. Saturation of the neutron yield occurs at a target thickness of about 8 ...10 radiation lengths.

We also note that the change of the transverse dimensions of the converter significantly affects on the neutrons yield. The neutrons yield per electron $\left(N_{n} / N_{e}\right)$ increases from 0.069 for the $P b$ target with size $10 * 10 * 50 \mathrm{~mm}^{3}$ to 0.088 for the $\mathrm{Pb}$ with size $60 \times 60 \times 50 \mathrm{~mm}^{3}$.

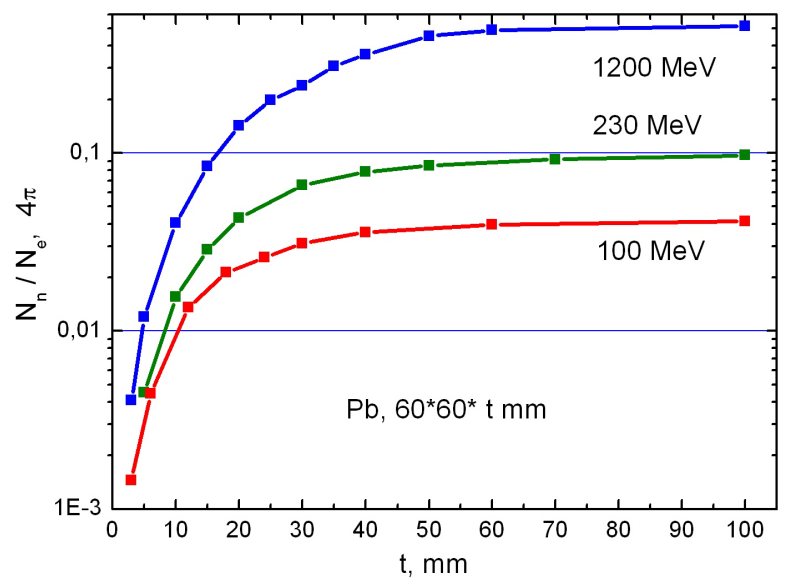

Fig.11. Calculated total neutrons yield in $4 \pi$ from the lead target under the action of electrons with an energy of 100, 230 and $1200 \mathrm{MeV}$ depending on the thickness of the target. The transverse dimensions of the target were $60 \times 60 \mathrm{~mm}^{2}$

Fig.12 shows the results of calculating the total neutrons yield under the action of the $100 \mathrm{MeV}$ electrons from the tantalum target. The results are in good agreement with the calculations [17].

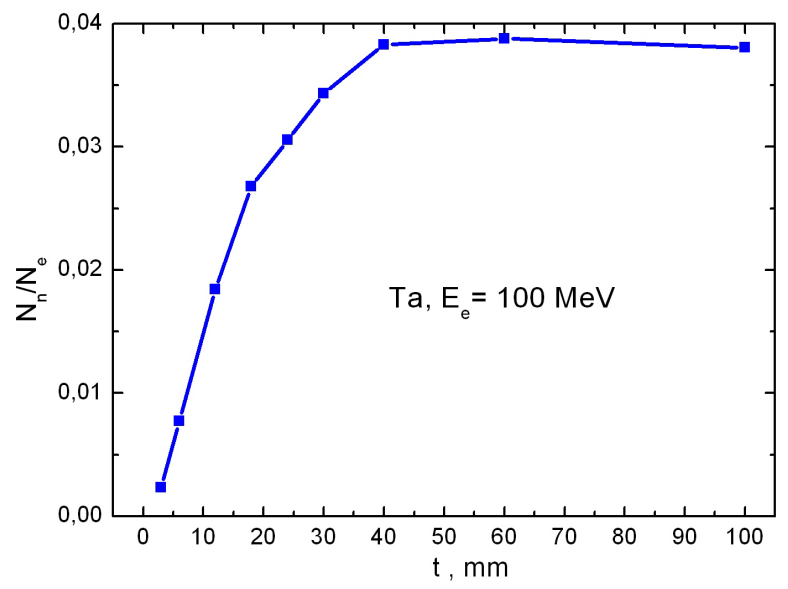

Fig.12. The results of calculating the total neutrons yield under the action of the $100 \mathrm{MeV}$ electrons from the tantalum target

From the obtained data, it can be seen that there are optimal sizes of the converter, and there is no sense in increasing the thickness of the converter more than the thickness of the neutron yield saturation. The dependence of the photoneutrons yield from targets $\mathrm{Pb}$ of $40 \mathrm{~mm}$ thick and $U$ of $50 \mathrm{~mm}$ thick from the incident electrons energy is shown in Fig.13. It can be seen that the dependence is close to linear (with the coefficient of proportionality C), excluding the energy regions close to the reaction threshold. The results for $\mathrm{Pb}$ are in good agreement with the results of the experiment [10]. 


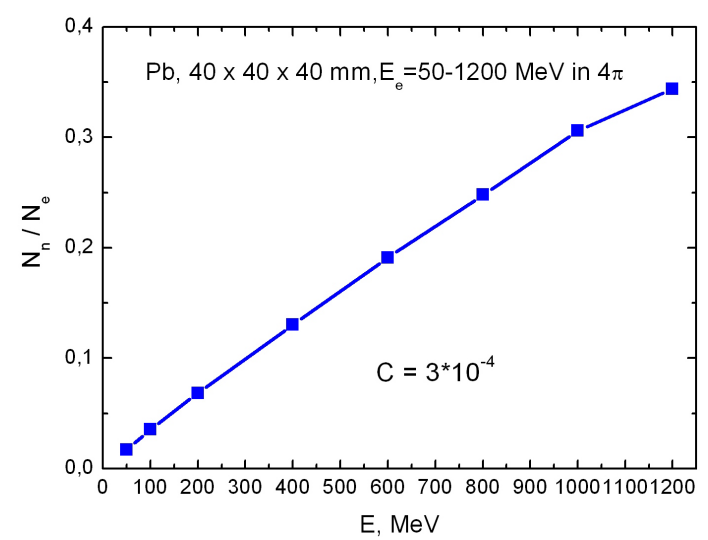

a) Pb target, thickness $40 \mathrm{~mm}$

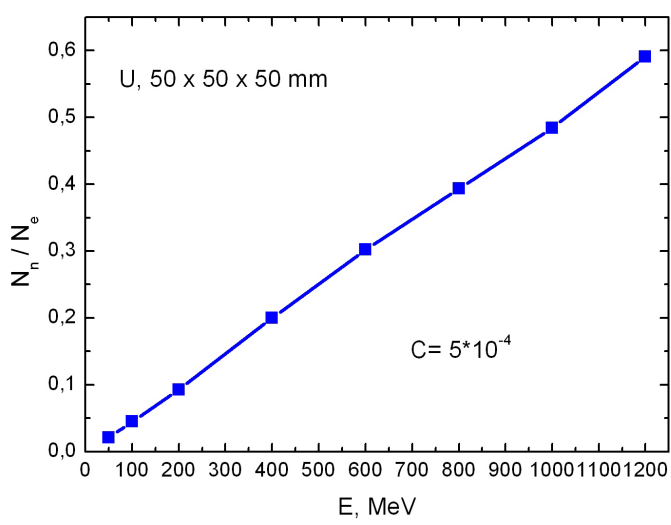

b) U target, thickness $50 \mathrm{~mm}$

Fig.13. The dependence of the photoneutrons yield from targets $\mathrm{Pb}$ of $40 \mathrm{~mm}$ thick and $U$ of $50 \mathrm{~mm}$ thick from the incident electrons energy

Tables 1-3 give a comparison of the calculated neutron yields in GEANT4 with the results of the experiments from work [16].

Table 1. Comparison of the calculated neutron yield in GEANT4 with the results of the experiment from work [16]. $E_{e}=34 \mathrm{MeV}$

\begin{tabular}{|c|c|c|c|}
\hline $\begin{array}{c}\text { Target } \\
\text { material }\end{array}$ & $\begin{array}{c}\text { Target } \\
\text { thickness, } \\
\mathrm{cm}\end{array}$ & $\begin{array}{c}\text { Measured } \\
\text { yield } N_{n} / N_{e} \\
\left(10^{-5} / \mathrm{MeV}\right)\end{array}$ & $\begin{array}{c}G E A N T 4 \\
\text { yield } N_{n} / N_{e} \\
\left(10^{-5} / \mathrm{MeV}\right)\end{array}$ \\
\hline$A l$ & 8.9 & 1.3 & 1.3 \\
$\mathrm{Cu}$ & 1.49 & 3.8 & 3.41 \\
$\mathrm{Ta}$ & 0.4 & 5.3 & 5.98 \\
$\mathrm{~Pb}$ & 0.57 & 6.2 & 6.31 \\
\hline
\end{tabular}

Table 2. Comparison of the calculated neutron yield in GEANT4 with the results of the experiment from work [16] for Ta, $3.74 \mathrm{~mm}$ thickness

\begin{tabular}{|c|c|c|}
\hline $\begin{array}{c}E_{e} \\
M e V\end{array}$ & $\begin{array}{c}\text { Experiment } \\
N_{n} / N_{e} \\
\times 10^{-4}\end{array}$ & $\begin{array}{c}\text { GEANT4 } \\
N_{n} / N_{e} \\
\times 10^{-4}\end{array}$ \\
\hline 10 & 0.88 & 0.065 \\
19 & 5.3 & 6.22 \\
28 & 13.7 & 14.62 \\
34 & 18.0 & 18.56 \\
\hline
\end{tabular}

Table 3. Comparison of the calculated neutron yield in GEANT4 with the results of the experiment from work [16] for Cu, $5.93 \mathrm{~cm}$ thickness

\begin{tabular}{|c|c|c|}
\hline $\begin{array}{c}E_{e} \\
M e V\end{array}$ & $\begin{array}{c}\text { Experiment } \\
N_{n} / N_{e} \\
\times 10^{-4}\end{array}$ & $\begin{array}{c}\text { GEANT4 } \\
N_{n} / N_{e} \\
\times 10^{-4}\end{array}$ \\
\hline 19 & 6.1 & 3.52 \\
28 & 21.5 & 19.4 \\
34 & 33.5 & 31.8 \\
\hline
\end{tabular}

The agreement was satisfactory, except for the threshold regions of the photonuclear reaction. The neutron yield calculations in GEANT4 were also compared with the results of papers $[18,19,22]$. We note that the difference in the calculations results of the neutrons yield in various papers is considerable (up to $20 \ldots 30$ percent).

The calculated angular dependencies of neutron yields for thick targets from $T a, W$ are shown in Figs.14,a,b.

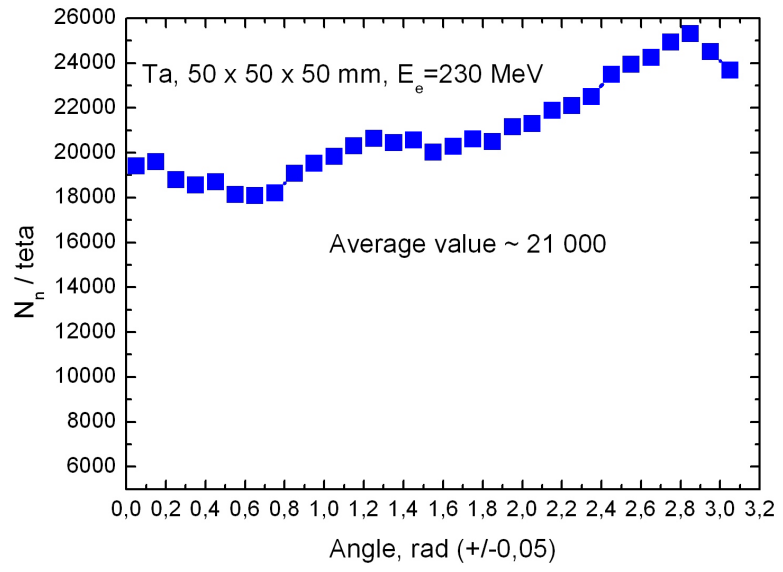

a) Ta target, dimensions $50 * 50 * 50 \mathrm{~mm}^{3}$, $E_{e}=230 \mathrm{MeV}$

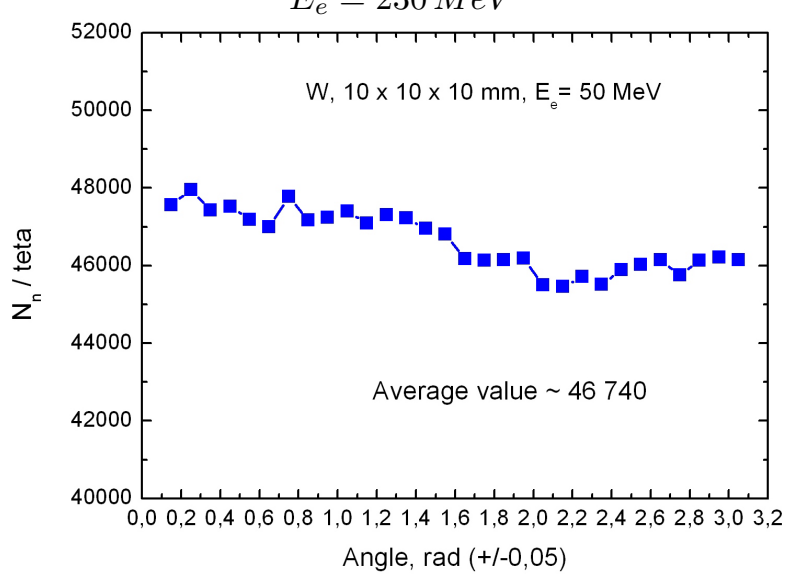

b) $W$ target, dimensions $10 * 10 * 10 \mathrm{~mm}^{3}$, $E_{e}=50 \mathrm{MeV}$

Fig.14. Calculated angular dependencies of neutron yields for thick $T a, W$ targets

The angular distribution of neutrons is close to isotropic, and it agrees well with the experimental results [10] and calculations [20]. 


\section{PASSING OF GAMMA-RADIATION AND NEUTRONS THROUGH BIOLOGICAL SHIELDING}

Numerical evaluations of the gamma-radiation spectra after the passing through the biological shielding separately of neutrons and bremsstrahlung gamma radiation were performed. In the center of the concrete ball was placed a thick Ta converter with size $20 \times 20 \times 40 \mathrm{~mm}^{3}$, on which the $E_{e}=100 \mathrm{MeV}$ electrons were directed. Bremsstrahlung, which passed through the walls of the ball, was registered at angles in the range $45^{\circ}$ to $135^{\circ}$ (sidewards). For this converter the number of neutrons is about 25 times smaller than the number of the incident electrons $\left(N_{n} / N_{e} \simeq 0.04\right)$.

Unfortunately, GEANT4 does not provide correct neutrons spectra, but satisfactorily estimates only the total neutrons number. Therefore, in further calculations we used the model spectra of the Talys program [21].

The neutrons from the sphere center were directed through the shielding in random directions. The neutrons passed through the shielding and gamma radiation from $(n, \gamma)$ nuclear reactions at the angles in the range $45 \ldots 135^{\circ}$ were registered.

Typical bremsstrahlung spectra and gammaradiation from $(n, \gamma)$ nuclear reactions at $45 \ldots 135^{\circ}$ angles after passing $50 \mathrm{~cm}$ of lightweight concrete are shown in Fig.15. Spectra have the similar form, but for gamma radiation from $(n, \gamma)$ nuclear reactions the large number of the gamma-lines are observed.Thus, after passing through concrete, the following spectra were obtained separately: 1. - bremsstrahlung spectra; 2. - for neutrons, two spectra separately: residual neutrons and gamma radiation from $(n, \gamma)$ nuclear reactions.

The comparison of the radiation exposure dose was carried out taking into account the quality factor $K$ associated with the relative biological efficiency of the radiation. Thermal neutrons have $K=5$, neutrons from $10 \mathrm{keV}$ to $100 \mathrm{keV}$ have $K=10$, neutrons from $100 \mathrm{keV}$ to $2 \mathrm{MeV}$ have $K=20$.

For the thickness of lightweight concrete 50 and $100 \mathrm{~cm}$, the radiation exposure of residual bremsstrahlung behind biological shielding exceeds the total contribution of gamma radiation from $(n, \gamma)$ reactions and residual neutrons by 15 and 30 times, respectively.

For $\mathrm{Fe}$ screen the situation changes. The total contribution of gamma radiation from $(n, \gamma)$ reactions and "residual" neutrons exceeds the "residual" bremsstrahlung by 15 times for $20 \mathrm{~cm}$ of $\mathrm{Fe}$, and in $\sim 100$ times for $40 \mathrm{~cm}$ of $\mathrm{Fe}$. This is due to a stronger absorption of gamma radiation in $F e$ and a less intense thermalization of neutrons in iron.

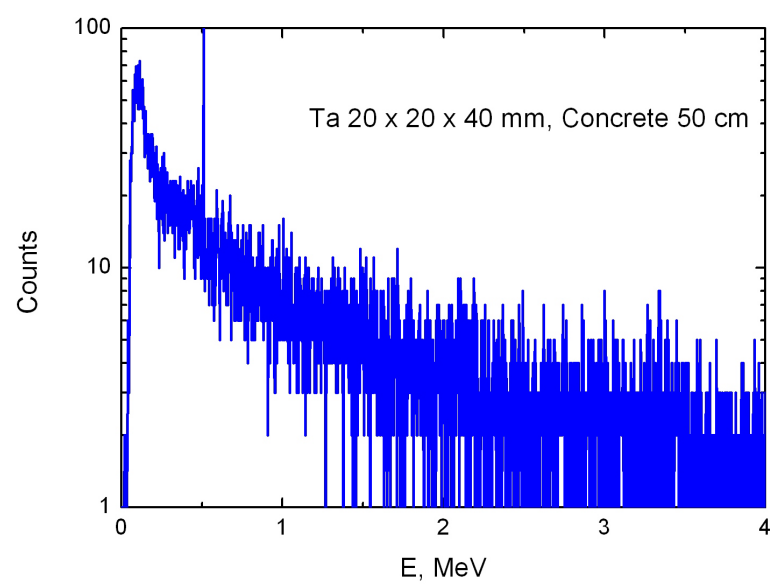

a) bremsstrahlung spectrum

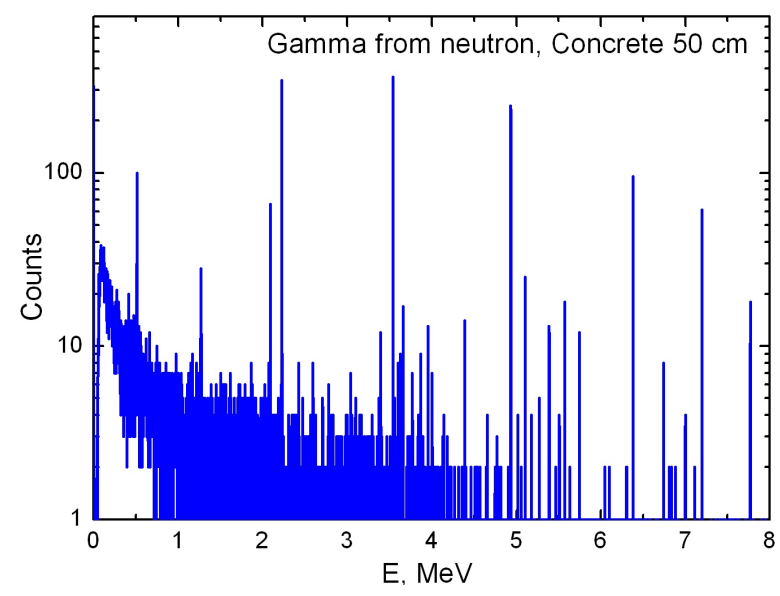

b) $\gamma$-radiation from $(n, \gamma)$ nuclear reactions

Fig.15. Bremsstrahlung spectra and gammaradiation from $(n, \gamma)$ nuclear reactions at $45 \ldots 135^{\circ}$ angle after passing $50 \mathrm{~cm}$ of lightweight concrete

For a $\mathrm{Pb}$ screen $5 \mathrm{~cm}$ thick, the neutron spectrum practically not changed; due to the quality factor in this case neutrons also dominate over the "residual" gamma radiation by a factor of 2 . For $10 \mathrm{~cm} \mathrm{~Pb}$, the neutrons exceed the residual bremsstrahlung by more than 4 times.

For $50 \mathrm{~cm}$ of paraffin, almost complete neutron absorption is observed. The "residual" bremsstrahlung radiation exceeds gamma radiation from $(n, \gamma)$ reactions by a factor of $\sim 150$ (Fig.16).

Thus, numerical estimates show that the radiation spectra after the passing of biological shielding separately for neutrons and bremsstrahlung depend on the shielding material. Qualitatively and in order of magnitude, the results of calculations in GEANT4 coincide with the results of paper [13], in which bremsstrahlung dominates (by an order of magnitude) for light concrete, and neutrons dominate (by an order of magnitude) in the case of heavy concrete. 


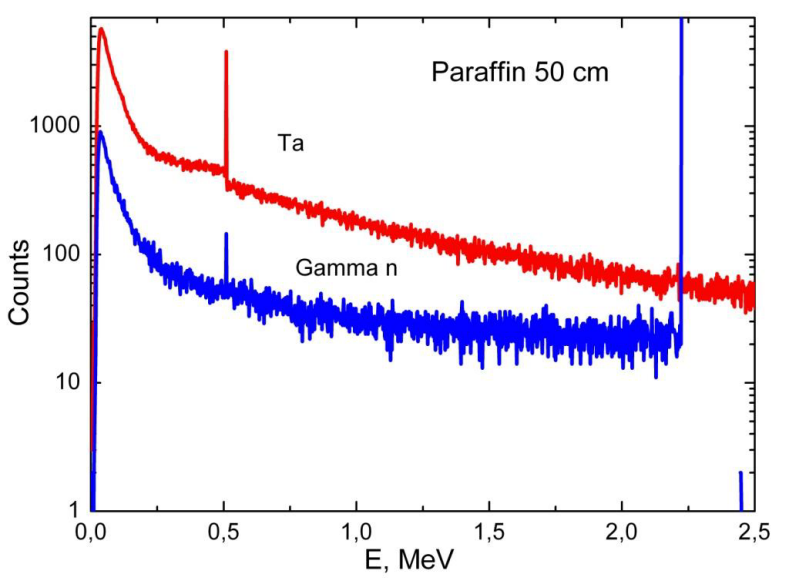

Fig.16. Spectra of "residual" bremsstrahlung - red line and gamma radiation from $(n, \gamma)$ reactions blue line at the sideward angles $45 \ldots 135^{\circ}$ angles after passage of $50 \mathrm{~cm}$ of paraffin

\section{CONCLUSIONS}

In GEANT4 were calculated the spectral-angular characteristics of the medium-energy electrons bremsstrahlung for various amorphous targets. The angular distributions of the radiation yield from converters of various thicknesses were calculated at angles in the range $0 \ldots 45^{\circ}$ (forward), $45 \ldots 135^{\circ}$ (sidewards) and $145 \ldots 180^{\circ}$ (back). The total yield of gamma radiation to the forward and backward hemispheres was calculated depending on the thickness of the converter.

The calculation was made of the total yield of neutrons from photonuclear reactions for targets with different thickness and atomic charge. The neutrons yield increased with increasing converter thickness and the energy of the incident electrons on the target. The numerical values of the total neutron yield agree satisfactorily with the experiment. The angular distribution of neutrons is close to isotropic. Numerical estimates of the radiation spectra after the passing of the biological shielding were performed for neutrons and bremsstrahlung. It is shown that the ratio of the radiations yield depends on the shielding material. For lightweight concrete the "residual" bremsstrahlung is dominant. For heavy shielding material the situation reversed and neutrons radiation dominated.

\section{References}

1. Electron and Positron Incident. //http://geant4.web.cern.ch/geant4/

2. S.M. Seltzer and M.J. Berger. Bremsstrahlung spectra from electron interactions with screened atomic nuclei and orbital electrons // Nucl. Inst. Meth. Phys. Res. 1985, v.B12, p.95-134.

3. A.N. Dovbnya, N.A. Dovbnya, V.I. Nikiforov, V.L. Uvarov. The method for analysis and optimization of the e, x-beam path of electron linac-based radiation installations // Problems of Atomic Science and Technology. Series "Nuclear Physics Investigations". 2006, v.47, N3, p.194196.

4. N.I. Ayzatsky, V.I. Nikiforov, A.V. Torgovkin, et al. Comparative analysis of photonuclear isotope genera-tion in the circuits with and without the bremsstrahlung converter //Problems of Atomic Science and Technology. Series "Nuclear Physics Investigations. 2008. N5 (50), p.194-197.

5. A.N. Dovbnya, V.V. Mitrochenko, V.I. Nikiforov, et al. An increase of ${ }^{99} \mathrm{Tc}$ yield under mixed $\gamma, n$-irradiation of target from natural molybdenum //Problems of Atomic Science and Technology. Series "Nuclear Physics Investigations". 2012. N4(80), p.151-154

6. A.N. Dovbnua, A.S. Deiev, V.A. Kushnir et al. Experimental results on cross sections for ${ }^{7} \mathrm{Be}$ photoproduction on $C^{12}, N^{14}$, and $O^{16}$ nuclei in the energy range of $40 . . .90 \mathrm{MeV} / /$ Physics of Atomic Nuclei, July 2014, v.77, Issue 7, p.805808.

7. G.L. Bochek, O.S. Deiev and N.I. Maslov. Measurement of the energy distribution of bremsstrahlung using Compton scattering //Journal of Surface Investigation: X-ray, Synchrotron and Neutron Techniques. 2012, v.6, N2, p.356-361.

8. G.L. Bochek, O.S. Deiev, N.I. Maslov. Energy and angular characteristics of electron bremsstrahlung for different converter //Problems of Atomic Science and Technology. Series "Nuclear Physic Investigations". 2012, N3(79), p.223-225.

9. G.L. Bochek, O.S. Deiev, V.K. Voloshin, N.I. Maslov. Measurement of intense X-Ray spectra: Methods based on CXR and Ross filter //Journal of Surface Inves-tigation. X-ray, Synchrotron and Neutron Techniques. March 2013, v.7, Issue 2, p.339-346.

10. V.I. Noga, Yu.N. Ranyuk, Yu.N. Telegin, P.V.Sorokin. The neutron yield from thick $\mathrm{Pb}$ target from high energy electrons: Preprint, KIPT 86-10, Kharkiv, 1978, 12 p.

11. O.S. Deiev, A.A. Mazilov, A.V. Mazilov et al. The research of X-ray and gamma radiation absorption by layered structures //Problems of Atomic Science and Technology. Series "Nuclear Physics Investigations". 2016, N3(103), p.105-110.

12. O.S. Deiev. GEANT4 simulation of neutron transport and scattering in media // Problems of Atomic Science and Technology. Series "Nuclear Physic Investigations". 2013, N3(85), p.236-241.

13. Z.Zhong, Y. Gohar. Electron Accelerator Shielding Design of KIPT Neutron Source Facility //Nuclear Engineering and Technology. 2016. 
14. I.E. Vnukov, S.A. Vorob'ev, B.N. Kalinin, et al. Experimental study of the albedo of a beam of gamma rays produced by ultrarelativistic electrons //Soviet Physics Journal. 1991, v.34, N6, p.555-564.

15. T. Vanaudenhove, F. Stichelbaut, A. Dubus et al. Monte Carlo calculations with MCNPX and GEANT4 for general shielding study //Progress in Nuclear Science and Technology. 2014, v.4, p.422-426.

16. M.C. White, R.C. Little, M.B. Chadwick. Photonuclear physics in $M C N P(X) / /$ Proceedings of the ANS on Nuclear Applications of Accelerator Technology, Long Beach, California. 1999, Nov. 14-18.

17. V.C. Petwal, V.K. Senecha, K.V.Subbaiah, et al. Optimization studies of photo-neutron production in high-Z metallic targets using high energy electron beam for ADS and transmutation //Indian Academy of Sciences. 2007, v.68, N2, p.235241.

18. K. Devan, A.K. Meaze and Guinyun Kim. PhotoNeutrons Produced at the Pohang Neutron Facility Based on an Electron Linac //Journal of the Korean Physical Society. 2006, v.49, N.1, p.89-96.

19. Lina Quintieri, Roberto Bedogni, Bruno Buonomo, et al. Photoneutron source by high energy electrons on high Z target: comparison between monte carlo codes and experimental data //Transactions of Fusion science and Technology. 2012, v.61, p.314.

20. A. Sari, F. Carrel, C. Jouanne, O. Petit, A. Lyoussi. Optimization of the photoneutron flux emitted by an electron accelerator for neutron interrogation applications using $M C N P X$ and TRIPOLI - 4 monte carlo codes / THPWA002 Proceedings of IPAC 2013, Shanghai, China, p.3630-3632.

21. TENDL-2015 Nuclear data library //http://www.talys.eu/home/

22. Radiological safety aspects of the operation of electron linear accelerators // Technical reports series No.188, International atomic energy agency, Vienna, 1979, A manual written by William P.Swanson , Stanford Linear Accelerator Center Stanford University.

23. G.L. Bochek, O.S. Deiev, V.N. Dubina, et al. Low-energy X-ray radiation after the biological shielding of electron accelerators //Problems of Atomic Science and Technology. Series "Nuclear Physics Investiga-tions". 2018, N3(115), p.172177.

\title{
ТОРМОЗНОЕ ИЗЛУЧЕНИЕ ЭЛЕКТРОНОВ И ВЫХОД НЕЙТРОНОВ ИЗ ТОЛСТЫХ КОНВЕРТОРОВ, ПРОХОЖДЕНИЕ ГАММА-ИЗЛУЧЕНИЙ И НЕЙТРОНОВ ЧЕРЕЗ ЗАЩИТУ
}

\author{
А. С. Деев, Г. Л. Бочек, В. Н. Дубина, С. К. Киприч, Г. П. Васильев, В. И. Яловенко, \\ В. Д. Овчинник, М. Ю. Шулика
}

В $G E A N T 4$ рассчитаны спектрально-угловые распределения тормозного гамма-излучения электронов средних энергий из аморфных мишеней-конверторов различной толщины и атомного заряда. Определен полный выход гамма-квантов в переднюю полусферу и под большими углами рассеяния в зависимости от толщины конвертора. Показано различие характеристик гамма-излучения для тонких и толстых мишеней. Проведен расчет выхода нейтронов за счет фотоядерных реакций для различных конверторов. Проведены численные оценки спектров излучения после прохождения биологической защиты отдельно для нейтронного и тормозного излучений.

\section{ГАЛЬМОВЕ ВИПРОМІНЮВАННЯ ЕЛЕКТРОНІВ І ВИХІД НЕЙТРОНІВ З ТОВСТИХ КОНВЕРТОРІВ, ПРОХОДЖЕННЯ ГАММА-ВИПРОМІНЮВАНЬ I НЕЙТРОНІВ КРІЗЬ ЗАХИСТ}

\author{
О. С. Деєв, Г. Л. Бочек, В. Н. Дубина, С. К. Кіпріч, Г. П. Василъєв, В. І. Яловенко, \\ В. Д. Овчінник, М. Ю. Шуліка
}

у GEANT4 розраховано спектрально-кутові розподіли гальмівного гамма-випромінювання електронів середніх енергій з аморфних мішеней-конверторів різної товщини і атомного заряду. Визначено повний вихід гамма-квантів у передню півсферу і під великими кутами розсіювання в залежності від товщини конвертора. Показано відмінність характеристик гамма-випромінювання для тонких і товстих мішеней. Проведено розрахунок виходу нейтронів за рахунок фотоядерних реакцій для різних конверторів. Проведено чисельні оцінки спектрів випромінювання після проходження біологічного захисту окремо для нейтронного і гальмівного випромінювань. 